\title{
ENSAYOS
}

\section{Pandemia ayer y hoy: una lectura pedagógica salesiana}

\author{
Pandemic yesterday and today: a salesian pedagogical understanding \\ Pandêmica ontem e hoje: uma leitura pedagógica salesiana
}

\author{
Marcelo Farfán Pacheco, $S D B^{a}$ \\ ${ }^{a}$ Universidad Politécnica Salesiana (IUS). Ecuador. \\ mfarfan@ups.edu.ec
}

\begin{abstract}
RESUMEN
El presente ensayo busca interpretar, a partir de una lectura pedagógica salesiana, la actual crisis causada por la pandemia del Covid-19. Para ello se acude a la memoria histórica acerca de la experiencia vivida por Don Bosco con sus jóvenes durante la epidemia del cólera que se desató en Turín en 1854, ubicando criterios y opciones pedagógicas que posibiliten una lectura salesiana de la actual crisis sanitaria global. Ese proceso metodológico ha permitido identificar algunos núcleos temáticos claves para abordar la acción educativa salesiana hoy: la centralidad de los pobres; la necesidad de la presencia educativa; la urgencia de la formación del "honesto ciudadano"; y la importancia de una espiritualidad de y para los jóvenes. Se concluye evidenciando la actualidad de la propuesta pedagógica salesiana a la hora de acompañar procesos educativos con jóvenes en tiempos de crisis.

Palabras claves: educación, sistema preventivo, pandemia.
\end{abstract}

\begin{abstract}
This essay intends to interpret, from a Salesian pedagogical understanding, the current crisis caused by Covid-19 pandemic. For this, it's important to consider Don Bosco's historical memory and experience during the cholera epidemic that occurred in Turin in 1854, emphasizing the criteria and pedagogical options that allow a Salesian understanding of the recent global health crisis. This methodological process allowed to identify some key thematic nuclei to approach Salesian educative action today: the centrality of the poor; the need for an educational presence; the urgency for the formation of "honest citizen"; and the importance of spirituality for young people. It concludes showing the relevance of the Salesian pedagogical presence specially accompanying educational processes with young people in times of crisis.
\end{abstract}

Key words: education, preventive system, pandemic.

\section{RESUMO}

Este ensaio procura interpretar, a partir de uma leitura pedagógica salesiana, a crise atual provocada pela pandemia de Covid-19. Para tanto, utiliza-se a memória histórica da experiência de Dom Bosco com seus jovens durante a epidemia de cólera que eclodiu em Torino em 1854, localizando critérios e opções pedagógicas que permitem uma leitura salesiana da atual crise global da saúde. Este processo metodológico permitiu identificar alguns núcleos temáticos fundamentais para abordar a ação educativa salesiana hoje: a centralidade dos pobres; a necessidade de uma presença educativa; a urgência da formação do "cidadão honesto"; e a importância da espiritualidade dos e para os jovens. Conclui mostrando a atualidade da proposta pedagógica salesiana para o acompanhamento dos processos educativos com os jovens em tempos de crise.

Palavras-chave: educação, sistema preventivo, pandemia. 


\section{INTRODUCCIÓN}

El objetivo de este ensayo es interpretar a la luz de los elementos pedagógico-pastorales que se pueden descubrir en la experiencia vivida por Don Bosco durante la epidemia de cólera (1854), la actual crisis sanitaria global causada por el COVID-19, con la intención de evidenciar opciones pedagógicas que inspiren a quienes estén comprometidos en la educación de los jóvenes.

La crisis producida por la presencia del COVID-19 ha sacudido las seguridades de las instituciones educativas, viéndose obligadas a repensar el propio funcionamiento y la inclusión de cambios tecnológicos, pedagógicos y de competencias en brevísimo tiempo. Del mismo modo que ha evidenciado serios límites en la educación, también ha dejado entrever grandes oportunidades que están a la espera de ser valoradas.

Desde la sensibilidad pedagógica salesiana, esta crisis ha traído a la memoria los acontecimientos vividos por Don Bosco a partir de agosto de 1854 a propósito de la llegada a Turín del denominado cólera asiático que afectó fatalmente a un gran número de su población más vulnerable. En esos meses la Casa Real de Saboya se refugió en el castillo del conde Cays en Caselette, como también hizo lo propio la élite turinesa encerrándose en sus casas de verano; mientras que en los barrios populares como en el que estaba ubicado Don Bosco con su naciente obra educativa, la epidemia causó gran número de muertes y dejó en orfandad a niños y jóvenes, pero no logró que el santo de los jóvenes abandonara su tarea educativa (Lemoyne, 1993, p. 69).

Precisamente este estudio pretende, por una parte, evidenciar las opciones educativas que inspiraron a Don Bosco a la hora de afrontar la epidemia y, por otra, ponerlas en diálogo con la actual situación de crisis sanitaria.

Don Bosco denominó Sistema Preventivo a su propuesta educativa nacida para dar respuesta a los jóvenes pobres, abandonados y en peligro. Dicho sistema se entiende como una "propuesta articulada hacia un dinamismo pedagógico" que se expresa en una triple intención: en un proyecto educativo de promoción integral de la persona de los jóvenes, en una espiritualidad juvenil y en un método pedagógico práctico (Dicasterio de la Pastoral Juvenil, 2014, p. 80). El propósito educativo de Don Bosco se expresa en el binomio: buen cristiano y honesto ciudadano.

Los elementos señalados han permitido descubrir los criterios, orientaciones y decisiones tomadas por Don Bosco para afrontar la crisis de la epidemia del cólera y que posibilitan sugerir opciones pedagógicas válidas para y más allá del "mundo" salesiano.

La pregunta que ha guiado la reflexión es la siguiente: ¿Qué desafíos educativos nos deja la crisis causada por el COVID-19 a partir de la perspectiva del Sistema Preventivo de Don Bosco?

De ese sugestivo diálogo de eventos ubicados en diferentes momentos históricos, se han podido identificar algunas opciones pedagógicas formuladas como desafíos importantes a la hora de acompañar educativamente a los jóvenes en este tiempo de crisis:

1) Los pobres como "lugar salesiano" en una sociedad globalizada que descarta a los últimos; 2) Presencia educativa que asegura un amor pedagógico más allá de las soluciones basadas en las tecnologías digitales; 3) Formación política a través del servicio y la solidaridad cuando el individualismo exacerbado amenaza la búsqueda del bien común; y 4) Espiritualidad que sostenga y sustente en profundidad los proyectos de vida cuando los eventos naturales e históricos pongan en duda todo sentido trascendente. 


\section{LOS POBRES COMO "LUGAR SALESIANO”}

A fines de julio de 1854 aparecieron los primeros casos de cólera en el Piamonte. Durante los tres meses que duró la epidemia se contagiaron en Turín 2500 personas, de los cuales 1400 murieron. En la zona popular de Valdocco, en donde estaba ubicado el Oratorio de Don Bosco, se enfermaron 800 en un mes, muriendo 500 de ellos (Lemoyne, 1993, p. 69). Don Bosco en persona, su madre Margarita y luego los jóvenes oratorianos van a salir a atender a los enfermos personalmente y a socorrerlos con los pocos recursos que tenían. Los destinatarios de sus cuidados van a ser los apestados que habían sido abandonados por sus familias en los barrios populares como Borgo Dora, Parque Real, Bértola (Lemoyne, 1993, p. 69). El cólera golpeó a los más pobres de modo fatal.

Don Bosco junto con su madre Margarita son los primeros en salir de su casa para ir al encuentro de los apestados que no tenían quien cuide de ellos. Esta actitud de Don Bosco y de su madre, evidencian la opción evangélica de poner al centro de todas las preocupaciones a los más débiles y vulnerables. Don Bosco vive en la periferia turinesa, pero va a la periferia humana y ese locus será la matriz que explica sus opciones pastoraleseducativas. Las Memorias Biográficas recuerdan:

Entre tanto, los casos de cólera eran cada vez más frecuentes en Turín y sus arrabales. En cuanto don Bosco se enteró de que la epidemia empezó a rondar por los alrededores del Oratorio, se aprestó a asistir a las víctimas. Mamá Margarita, que en otras ocasiones había demostrado tanto miedo por la vida del hijo, en ésta manifestó que era un deber suyo desafiar el contagio. (Lemoyne, 1993, p. 73).

De modo no muy diferente, la actual pandemia global ha segado la vida de los más débiles y ha impactado en las poblaciones más pobres y naciones socialmente desiguales. En muchos lugares ha prevalecido una no- ética de guerra que ha llevado a descartar a los ancianos y favorecer a los que tenían más posibilidades de sobrevivir a la acción del virus. Por otra parte, el impacto económico causado por la pandemia ha empobrecido más a la población y, particularmente, ha afectado los procesos educativos de niños y jóvenes.

En el caso América Latina el aumento del desempleo provocará el incremento de la tasa de pobreza y de pobreza extrema (CEPAL, 2020, p. 3). Eso significa que muchas familias de clase media en América Latina están retornando a la pobreza poniendo en riesgo los objetivos de desarrollo sostenible de la región: "Los desafíos estructurales de la pobreza, la profunda desigualdad en diferentes dimensiones y la debilidad de los sistemas de protección social y de salud han exacerbado la vulnerabilidad de la región ante la pandemia" (CEPAL, 2020, p. 3). La misma situación se está dando en otros contextos.

El retorno a la pobreza impacta en la sostenibilidad de los centros escolares ya que se prevé una disminución importante de la matrícula. Las escuelas y universidades católicas y privadas han alertado sobre esa situación que se está dando especialmente con los estudiantes más vulnerables (Wodon, 2020, p. 18).

Los avances en el acceso a la educación por parte de sectores con menor capital educativo provenientes de sectores populares, se pone en riesgo, ahondando las desigualdades de todo tipo. Mayor todavía está siendo el impacto en las familias vulnerables sin ingresos fijos que dependen del trabajo diario. 
Se prevé que las principales consecuencias en alumnos y familias de sectores populares que se beneficiaban de ofertas de educación privada serán: Pérdida del aprendizaje recibido, abandono escolar, desnutrición y afectación de la salud mental (Wodon, 2020, p. 15).

Particularmente nos interesa subrayar el impacto de la crisis en la vida de los jóvenes. La pandemia ha provocado incerteza, miedo, temor y especialmente ha profundizado la desconfianza en el futuro que ya era una actitud presente en los jóvenes antes de la misma. Gran número de desempleados son jóvenes recientemente graduados. Encontramos jóvenes con posgrados de alto nivel y sin trabajo, dependientes de los padres. Esta realidad amenaza la esperanza de las nuevas generaciones. Pero también cuestiona el modelo de formación de profesionales que todavía propone la universidad: más orientados al empleo que al emprendimiento. En definitiva, la crisis sanitaria ha incrementado los procesos de exclusión y marginación. En este sentido preocupa también el aumento del trabajo infantil que se prevé como una de las graves consecuencias de la pandemia (OIT, Iniciativa Regional América Latina y el Caribe del Trabajo Infantil y CEPAL, 2020, p. 3).

En este panorama la praxis pastoral y la experiencia pedagógica y espiritual de Don Bosco nos llevan a asumir dos desafíos: "salir" e ir al "lugar" de las víctimas. Don Bosco, ante la presencia de la epidemia del cólera, no huyó a refugiarse en una casa de verano como lo hizo la Casa Real de Saboya; sino que salió en búsqueda de los enfermos. En el Cuadro de Referencia de la Pastoral Juvenil se puede leer que la opción existencial de Don Bosco no estuvo motivada por una investigación sociológica o por alguna constatación sicológica, ni siquiera por una sensibilidad filantrópica; sino lo que lo movió fueron opciones nacidas del Evangelio. Don Bosco desarrolla un modelo educativo-pastoral caracterizado por la simpatía, la compasión, la cercanía con la gente y con los jóvenes pobres (Dicasterio de la Pastoral Juvenil, 2014, p. 26). Por tanto, los efectos devastadores de la crisis sanitaria global imponen un recolocarse en el "locus" pedagógico a partir del cual se actualiza el Sistema Preventivo: los jóvenes pobres, abandonados y en peligro. La tradición salesiana llama "primado de la caridad educativa" a ese conjunto de opciones, actitudes y procesos que lleva a un educador a buscar a "los últimos, a los más humildes, a aquellos que tienen mayores dificultades" (Dicasterio de la Pastoral Juvenil, 2014, p. 81).

\section{LA PRESENCIA EDUCATIVA COMO “SACRAMENTO” SALESIANO}

La actual pandemia se ha caracterizado, entre otras cosas, por la distancia y el aislamiento social que en el ámbito educativo ha llevado, por contraposición, a evidenciar la importancia de la presencialidad, de la relación personal, de los afectos en los procesos educativos. Éste es uno de los elementos claves en la pedagogía salesiana: la presencia afectiva del educador en medio de los jóvenes.

A inicios de la epidemia del cólera, Don Bosco con actitud paterna y con un enorme sentido práctico y de respeto a las normas, está presente y cuida personalmente de sus jóvenes. Con sano y concreto criterio educativo pide a los jóvenes que cumplan las normas médicas de la época, a pesar de las condiciones de pobreza en la que vivían.

La descripción que se encuentra en las Memorias Biográficas referente a los meses de la epidemia del cólera, evidencia en el Oratorio de Valdocco la existencia de una comunidad juvenil animada por la figura paterna de Don Bosco y materna de Mamá Margarita, en donde se vive un ambiente inspirado en los valores del evangelio que pauta 
el camino formativo que hacen los jóvenes oratorianos y que permitió afrontar y superar la epidemia:

Al esparcirse la noticia de que el mal empezaba a extenderse por la ciudad, don Bosco demostró ser el padre amoroso y el buen pastor de sus hijos. Empleó todas las precauciones posibles, aconsejadas por la prudencia y la ciencia, para no tentar al Señor. Hizo limpiar bien los locales, preparó otras habitaciones para disminuir el número de camas en los dormitorios, y mejoró la comida, lo cual le ocasionó notables gastos. (Lemoyne, 1993, p. 70).

La pandemia causada por el covid-19 ha recolocado el tema escuela entendida como comunidad educativa entre los más importantes para el funcionamiento de la sociedad. Las familias han redescubierto la importancia de la educación, el valor y la necesidad de los maestros, lo esencial de la educación como espacio de socialización, de los afectos, de la interrelación incluso más allá de la familia. Ha quedado muy claro que educar es mucho más que transmisión de contenidos académicos y es sobre todo un acto social, afectivo, emotivo que exige cercanía humana.

Durante la pandemia la mediación tecnológica ha "salvado" a la institución escolar y ha permitido valorar la potencialidad del aprendizaje a distancia, pero también ha dejado ver sus limitaciones. Es cierto que la tecnología ha "acercado" virtualmente a los actores educativos, la escuela ingresó a los espacios de la familia y las familias se implicaron en las actividades escolares de los hijos; sin embargo, quedó en evidencia la necesidad imperiosa de diferenciar espacios, de distinguir roles, y especialmente la constatación de la necesidad de los amigos, de los maestros más allá de la importante relación familiar. Con seguridad una de las lecciones que nos ha dejado la pandemia es que la educación es una cuestión de relación de personas en la que puede haber válidas y necesarias mediaciones tecnológicas, pero que finalmente sin rostros cercanos se vuelve imposible.

Por otra parte, cuando se habla de presencia, la educación no se reduce a un proceso de relación interpersonal solamente, sino que hace referencia a una "presencia" que es comunitaria. La educación crea comunidad y se alimenta de ella.

Por ello, la escuela no resiste una crisis si no ha construido alianzas en donde la comunidad educativa sea el sujeto de todos los procesos educativos. Mientras más la educación sea vista como un servicio que se oferta, más en riesgo se pondrá su sostenibilidad. La educación salesiana no es un producto que se ofrece, es un signo de amor que una comunidad educativa expresa a los jóvenes pobres.

El Rector Mayor de los salesianos, ha definido la presencia del educador como el "sacramento salesiano" (Fernández, 2020b, p. 8). Categoría con una fuerte carga teológica usada para referirse al signo carismático que todo educador y toda comunidad educativa está llamada a ofrecer a los jóvenes: estar educativamente en medio de ellos. No hay educación sin presencia personal alegre y gratuita que escucha, dialoga y acompaña y sin comunidad educativa entendida como red de afectos que educa. 


\section{LA URGENCIA DE LA FORMACIÓN DEL “HONESTO CIUDADANO” DESDE LA SOLIDARIDAD Y EL SERVICIO}

Si bien es verdad que "no existe posibilidad de gobernar racionalmente una pandemia" (Bonino, 2020, p. 28); sin embargo, la crisis sanitaria ha dejado al descubierto lo que ya se conocía: la gravísima ausencia de sentido del bien común en la clase política. Las decisiones y criterios para la gestión de la pandemia se han polarizado entre priorizar la salud de la población o favorecer la sostenibilidad económica. Muchos gobiernos y partidos políticos han preferido salvar a las empresas que cuidar a la población. Algunas dirigencias más interesadas en sus cálculos políticos que en el bien de la población, negaron los efectos del virus, lo ridiculizaron o se alinearon con las teorías de la conspiración; al mismo tiempo que se constataba un creciente e incontrolable aumento del número de víctimas entre la población más vulnerable.

De manera inaudita, en algunos países surgieron numerosos casos de corrupción justamente durante la pandemia aprovechándose de la tragedia para hacer negocios ilícitos en torno al tema de la salud.

Por otra parte, es importante tener en cuenta la vinculación cada vez mayor entre objetivos políticos y tecnologías de la comunicación: "Con la pandemia nos dirigimos hacia un régimen de vigilancia biopolítica. No solo nuestras comunicaciones, sino incluso nuestro cuerpo, nuestro estado de salud se convierten en objetos de vigilancia digital" (Han, 2020 , s.p.). De hecho, en muchas naciones la pandemia ha sido utilizada para aumentar los controles sobre la población por parte de los gobiernos poniendo entre paréntesis las libertades individuales.

Asimismo, los discursos y prácticas discriminatorias, racistas, nacionalistas y xenofóbicas se han aprovechado de la pandemia para justificar políticas anti-migrantes, esto lo podemos constatar especialmente en el contexto europeo con los movimientos soberanistas o nacionalistas. Por otro lado, también la pandemia ha dejado ver irresponsabilidad ciudadana, quemeimportismo e irrespeto de normas promulgadas para prevenir contagios y salvar vidas.

La pandemia ha visibilizado la profunda desigualdad social que afecta a todas las naciones, la corrupción generalizada presente en la sociedad y en las funciones del estado, la brecha cada vez más honda entre ética y política y un individualismo exacerbado que no considera importante la vida del otro. Esta realidad vuelve urgente replantear la relación educación-política y la misma formación política de los jóvenes. Desde la perspectiva pedagógica salesiana es fundamental profundizar en el significado del propósito educativo formulado por Don Bosco del buen cristiano y honesto ciudadano (Fernández, 2020a, p. 3).

El colapso del sentido de responsabilidad ciudadana evidenciado en la crisis sanitaria lleva necesariamente a pensar en los desafíos educativos. Con seguridad resulta iluminador acudir a la experiencia de Don Bosco en el modo de enfrentar la epidemia del cólera. De hecho, se encuentran algunos elementos que expresan el sentido "político" de Don Bosco de frente a la crisis que le tocó vivir: colaboración con la ciudad, especialmente con la atención a los enfermos, respeto por las normas que cuidan la vida, solidaridad y servicio junto con los jóvenes oratorianos.

Ante todo, Don Bosco se muestra audaz y temerario al invitar a los chicos de su Oratorio a unirse en el servicio a los apestados por el cólera. Como un buen ciudadano se hace eco del llamado del alcalde de Turín para colaborar con la atención de los enfermos, 
desatando una impresionante honda de solidaridad y capacidad de servicio en los jóvenes en medio de serios riesgos para la propia vida:

Nació entonces en la mente de don Bosco una idea grandiosa: idea que le llevó a tomar una singular decisión... un día, reunió don Bosco a sus jóvenes y les dirigió unas sentidas palabras. Les describió el miserable estado en que se hallaban muchos enfermos...les habló del hermosísimo acto de caridad que suponía dedicarse a atenderlos... de cómo en todas las epidemias había habido cristianos generosos, que desafiando a la muerte, habían estado al lado de los pacientes ayudándolos y atendiéndolos física y espiritualmente. Les dijo que el alcalde en persona había solicitado enfermeros y asistentes; que don Bosco y algunos más ya se habían ofrecido y concluyó manifestando su deseo de que algunos de sus muchachos les acompañaran en aquella obra de misericordia.

Las palabras de don Bosco no cayeron en el vacío. Los muchachos del Oratorio las acogieron religiosamente y se portaron como hijos de tal padre. Catorce de ellos se presentaron inmediatamente, dispuestos a secundar sus deseos, y dieron su nombre para ser inscritos en la lista de la comisión sanitaria; y, pocos días después, siguieron su ejemplo otros treinta (Lemoyne, 1993, p. 73).

Es muy interesante constatar la incidencia que tuvo en la ciudad de Turín el gesto de servicio de los chicos del Oratorio y, al mismo tiempo, el impacto que produjo en sus propias vidas alcanzando serenidad y alegría en el servicio a los enfermos. Fue una escuela práctica de ciudadanía, motivada por la fe cristiana que profesaban los chicos:

Apenas se supo que los muchachos del Oratorio se habían entregado al cuidado y asistencia de los apestados y que eran excelentes enfermeros, se multiplicaron de tal modo las llamadas que, a la semana, hubo que cambiar el horario establecido. Parientes, vecinos y conocidos y el mismo Ayuntamiento, todos recurrían a don Bosco, de suerte que los jóvenes estaban continuamente en movimiento. Había días en que apenas si podían tomar un bocado de pan y, a lo mejor, deprisa y en la misma casa del paciente. De noche, era un continuo ir y venir de uno que se acostaba, de otro que se levantaba; y más de una noche se la pasaron en vela, al lado de los enfermos sin punto de reposo, pero alegres y contentos (Lemoyne, 1993, p. 75).

El "honesto ciudadano" supone en el actual contexto una formación al sentido político, a la participación sociopolítica, al ejercicio de la democracia, a la responsabilidad por el otro, a la superación del individualismo. Cuando la educación es solamente una respuesta a la demanda laboral del mercado, o una herramienta para la búsqueda del éxito económico, o reproductora de las graves desigualdades sociales, no podemos sorprendernos que la corrupción ya esté presente en el corazón de los jóvenes, antes que se manifieste a nivel de la res pública. En ese sentido el Rector Mayor afirma:

Como educadores, debemos actuar y favorecer la honradez y la no-corrupción ¿Cómo? Desde la preventividad. Es muy común escuchar en la actualidad tantos 'cantos de sirena' que propagan como lo más natural el poder conseguir todo fácilmente por caminos que corrompen el interior de la persona y dañan su integridad, la fortaleza, la verdad de lo que somos. (Fernández, 2020a, p. 21). 
Don Bosco formó a los jóvenes en la responsabilidad social mediante el servicio a los pobres. En la mente de don Bosco no hay dicotomía entre el creyente y el ciudadano: el auténtico cristiano es un auténtico ciudadano.

Hoy la formación política pasa por el compromiso a favor de los migrantes, la defensa de la casa común, la defensa de los derechos humanos, el respeto por la dignidad humana de toda persona sea cual sea su condición religiosa, etaria, sexual o étnica.

La pandemia ha dejado en claro la importancia de fortalecer la comunidad familiar, la comunidad local, los auténticos liderazgos políticos y la formación de ciudadanos con sentido de lo público.

\section{LA IMPORTANCIA DE UNA ESPIRITUALIDAD EN EL PROCESO EDUCATIVO}

La pandemia no solo que ha provocado una caída económica mundial, también ha trastocado la interioridad de las personas poniendo en crisis los significados de la vida y de la muerte. Basta recordar que miles de personas han tenido que morir en la más absoluta soledad y sus familias impedidas de despedirse de sus seres queridos. Miles han vivido y viven la amargura de separarse para siempre sin los ritos simbólicos que alivian el dolor de la muerte. Esta experiencia vivida por tantas personas en carne propia ha provocado angustia, temor, impotencia y sinsentido. A la muerte la hemos visto recorrer campante en las decenas de camiones militares llevando ataúdes por las calles de las ciudades de Lombardía, en los miles de fosas abiertas al apuro en Manaos, en las cajas de cartón con cadáveres en las calles de Guayaquil a la espera de un trámite burocrático. El virus ha derrumbado seguridades ideológicas y ha traído a la muerte de vuelta a la conciencia colectiva. De ahí que virus y encerramiento han hecho que emerjan preguntas fundamentales sobre el sentido de la vida y la muerte y han obligado a encontrar razones más profundas para existir. Las preguntas acerca del sentido de lo que acontece se han hecho presentes también al interior de las aulas virtuales escolares. Por tanto, el "desierto" de sentido provocado por la pandemia deja entrever la importancia de la dimensión espiritual en la acción educativa.

Desde una perspectiva más optimista hay que reconocer que en estos meses se han puesto de relieve grandes valores humanos: ha sorprendido el sentido de solidaridad, la compasión, el sacrificio a favor de los otros, el buen criterio de miles de personas comunes, la capacidad de resistencia, la ayuda desinteresada, la creatividad, etc. Grandeza humana y fortaleza interna-espiritual se han hecho presentes en esta crisis.

Por su parte, Don Bosco no se recluyó de modo defensivo ni perdió la perspectiva de fe ante la trágica situación que provocó el cólera en Turín. Al contrario, no solamente que va a invitar a los jóvenes del Oratorio a que se pongan al servicio de los enfermos; sino que ante todo les ayudará a hacer una lectura de fe de los acontecimientos. Efectivamente, según la mentalidad teológica de la época, Don Bosco interpreta la tragedia como una invitación divina a una vida cristiana auténtica, transformando la epidemia en oportunidad educativa para que los jóvenes asuman normas y valores espirituales para el propio desarrollo personal:

He aquí, pues, queridos hijos míos, los remedios que os propongo para libraros del cólera. Son casi los mismos prescritos por los médicos: Sobriedad, templanza, tranquilidad de espíritu y entereza. Pero, ¿Cómo podrá tener tranquilidad de espíritu y 
entereza el que vive en pecado mortal, el que no está en gracia de Dios, el que sabe que si muere va al infierno? (Lemoyne, 1993, p. 71).

Más allá de coincidir o no con una determinada visión religiosa, lo fundamental en la experiencia de Don Bosco es la convicción de que no puede haber auténtica educación sin una apertura a lo trascendente. Para esto anima y acompaña a los jóvenes a interpretar los eventos históricos desde ese horizonte de sentido. Les señala objetivos de vida, valores cristianos y humanos a partir del contexto que los jóvenes están experimentando. El tema del cólera no fue únicamente un tema médico o de salud pública, sino también de sentido, de opciones éticas para la vida personal y social. Por tanto, la lectura que hace don Bosco es de carácter teológico con consecuencias pedagógicas, consiguiendo educar a través de las experiencias vitales:

También los muchachos que sólo asistían al Oratorio festivo empezaron a llevar una vida ejemplar. Los días de fiesta acudían puntualmente a las funciones sagradas, muchos recibían los santos sacramentos y, durante la semana, daban auténtico ejemplo a quienes los veían o trataban (Lemoyne, 1993, p. 73).

La propuesta educativa de Don Bosco no concluye con el ejercicio de un amor educativo y social liberadores de las condiciones de miseria en las que se encuentran los jóvenes pobres; sino que es un amor pedagógico basado en sus convicciones de fe. Para Don Bosco la propuesta educativa encuentra su sentido y vigor a partir de la convicción de que "los jóvenes son personas llamadas a la plenitud real de la vida, la comunión con Dios y con el prójimo". (Dicasterio de la Pastoral Juvenil, 2014, p. 88). Esa dimensión trascendente de la educación es la fuente del optimismo tan típicamente salesiano que hace que las oscuridades de la historia y los eventos trágicos no hagan colapsar el sentido de la vida y los proyectos personales, comunitarios y sociales. Encontramos en el Cuadro de Referencia de la Pastoral Juvenil expresada esta necesidad hoy urgente:

(...) Será necesario educar el sentido de la trascendencia y dar respuesta a las grandes preguntas sobre el sentido de la vida y de la muerte, del dolor y del amor, sin ocultar el rayo de luz que nos viene desde nuestra fe (Dicasterio de la Pastoral Juvenil, 2014, p. 89).

Con seguridad uno de los propósitos de la educación salesiana es acompañar para que los jóvenes construyan una visión unitaria de la vida abriéndose a la gratuidad de Dios vivida en el encuentro libre y pleno con Cristo. Asimismo, no deja de ser un desafío para una educación auténticamente laica comprenderse como una hermenéutica que permita descifrar la historia y sus significados.

Las Constituciones Salesianas hablan del Sistema Preventivo entendido como un acompañamiento para que los jóvenes adquieran convicciones sólidas y asuman el "proceso de crecimiento de su humanidad en la fe" (Sociedad de San Francisco de Sales, 2017, p. 38). 


\section{CONCLUSIÓN}

La lectura de la experiencia educativa vivida por Don Bosco durante la epidemia del cólera de 1854 nos ha permitido evidenciar algunos desafíos pedagógicos que resultan prioritarios en el actual contexto pandémico.

Los retos encontrados contribuyen a superar el riesgo de entender la crisis como algo coyuntural que se soluciona con el acceso y mejoramiento de tecnologías digitales. Como clama Philippe Meirieu: “¡Dejemos de idolatrar lo digital!” porque solo resuelve problemas de quien no tiene problemas (Deoubre, 2020).

Es necesario, como lo hemos demostrado, asumir como punto de partida la decisión de hacer del mundo de los jóvenes pobres el "locus" pedagógico que obliga a repensar los procesos educativos. En coherencia con esa opción, afirmar la presencia personal como mediación pedagógico-afectiva irrenunciable; y reconducir los propósitos educativos hacia la formación política y espiritual en cuanto dimensiones que sintetizan la integralidad y la urgencia de la educación de los jóvenes en el actual contexto.

Por otra parte, este ensayo muestra la importancia de ahondar en una triple temática que ha sido enunciada durante esta reflexión. La primera hace referencia a las posibilidades de la virtualidad como una modalidad de presencia educativa en un escenario de creciente desarrollo de tecnologías digitales aplicadas a la escuela. Vásquez señala que la pandemia ha demostrado la importancia de la escuela como espacio de encuentro, comunicación y socialización (Vazquez, 2020, p. 4). Si la educación es interrelación, entonces es necesario plantearse si ese objetivo es viable y cómo en una modalidad virtual.

Una segunda, tiene que ver con la resignificación de la educación política en la escuela en un marco cultural de exaltación del individualismo y mercantilización de la educación por parte de las grandes corporaciones. Temas como las nuevas sensibilidades políticas de los jóvenes, la comunidad educativa como ejercicio de participación, el servicio como escuela de formación ciudadana, la solidaridad ecológica y humana como espacio de construcción de una conciencia planetaria... son aspectos que requieren ser profundizados.

Finalmente, la crisis sanitaria y su impacto en la vida interior de las personas, en la cosmovisión, en los significados de la vida, nos hace pensar en la importancia de reinterpretar el sentido de la educación laica. Nos parece que ésta no se contrapone con una educación que asuma la ricas y variadas expresiones espirituales de las personas, culturas y pueblos. Es éste un tema de gran urgencia y riqueza que necesita ser abordado más allá de cualquier afiliación religiosa.

La pandemia nos ha obligado a mirar de otro modo la realidad cuestionando la totalidad de nuestras seguridades, pero nos ha dado la oportunidad para redescubrir lo verdaderamente esencial en el campo educativo.

\section{REFERENCIAS BIBLIOGRÁFICAS}

Bonino, E. (2020). Le lezioni politiche della pandemia. En CNEL, Il mondo che verrà. Interpretare e orientare lo sviluppo dopo la crisi sanitaria globale. Roma: Consiglio Nazionale dell'Economia e del Lavoro.

CEPAL. (2020). Salud y economía: una convergencia necesaria para enfrentar el COVID-19 y retomar la senda hacia el desarrollo sostenible en América Latina y el Caribe. Santiago: CEPAL. 
Deoubre, O. (13 de mayo de 2020). Philippe Meirieu: ¡Dejemos de idolatrar lo digital! Recuperado el 30 de octubre de 2020, de https://vientosur.info/philippe-meirieu-dejemos de-idolatrar-lodigital/

Dicasterio de la Pastoral Juvenil. (2014). La Pastoral Juvenil Salesiana. Cuadro de Referencia. Roma: S.D.B.

Fernández, A. (2020a). Buenos cristianos y honrados ciudadanos. Recuperado el 26 de septiembre de 2020, de https://www.sdb.org/es/CG28/Documenti

. (2020b). Propuesta Programática del Rector Mayor a la Congregacion Salesiana después del Capitulo General 28. Recuperado el 27 de septiembre de 2020, de https://www.sdb.org/es/ CG28/Documenti

Han, B. C. (2020). Byung-Chul Han: Viviremos como en un estado de guerra permanente. Recuperado el 17 de noviembre de 2020, de https://www.lavanguardia.com/cultura/20200512/481122883308/ byung-chul-han-viviremos-como-en-un-estado-de-guerra-permanente.html

Lemoyne, J. (1993). Memorias Biográficas de San Juan Bosco. Madrid, España: CCS.

OIT, Iniciativa Regional América Latina y el Caribe Libre del Trabajo Infantil y CEPAL. (2020). La pandemia por Covid-19 podría incrementar el trabajo infantil en América Latina y el Caribe. Recuperado el 24 de septiembre de 2020, de Nota técnica N. 1: https://www.iniciativa2025alc. org/sites/default/files/nota-tecnica1-trabajoinfantil-covid19_ES_VF.pdf

Vázquez, M. (2020). La educación ante la pandemia y el aislamiento social, preventivo y obligatorio. Recuperado el 30 de octubre de 2020, de HYPERLINK "http://repositorio.unlz.edu.ar:8080/ handle/123456789/484" http://repositorio.unlz.edu.ar:8080/handle/123456789/484

Sociedad de San Francisco de Sales. (2017). Constituciones y Reglamentos Salesianos de Don Bosco. Madrid, España: CCSS.

Wodon, Q. (2020). Global Catholic Education Report 2020: Achievements and Challenges at a Time of Crisis. Roma: International Office of Catholic Education. 
